ONLINE MUTATION REPORT

\title{
The common SCN5A mutation R1 193Q causes LQTS-type electrophysiological alterations of the cardiac sodium channel
}

\author{
Q Wang, S Chen, Q Chen, X Wan, J Shen, G A Hoeltge, A A Timur, M T Keating, G E Kirsch
}

J Med Genet 2004;41:e66 (http://www.jmedgenet.com/cgi/content/full/41/5/e66). doi: 10.1136/jmg.2003.013300

L ong QT syndrome (LQTS) is a prototypic arrhythmic disorder that is characterised by prolonged QT interval (or QTC) on electrocardiograms (ECGs), syncope, and sudden death from episodic ventricular tachyarrhythmias, specifically torsade de pointes. ${ }^{1-4}$ LQTS causes sudden deaths in young, otherwise healthy, individuals, and in many cases the first symptom is sudden death. Both genetic and acquired factors contribute to the pathogenesis of LQTS. Predisposing genetic mutations have been identified in six genes. These include the cardiac potassium channel genes KvLQTI or KCNQ1 (chromosome 11 pl5.5, LQT1), ${ }^{5-7}$ HERG or KCNH2 (7q35-36, LQT2), ${ }^{8}$ KCNE1 (2lq22, LQT5), ${ }^{10}$ and KCNE2 (2lq22, LQT6), ${ }^{11}$ the cardiac sodium channel gene SCN5A (3p2 l-24, LQT3), ${ }^{12}{ }^{13}$ and the non-ion channel ankyrin- $B$ gene encoding a protein that links ion channels to the cytoskeleton (4q25-27, LQT4). ${ }^{14}$

Acquired long QT syndrome (aLQTS) is LQTS caused by factors such as bradycardia, cardiac ischaemia, metabolic abnormalities (including hypocalaemia and hypomagnesaemia), starvation (anorexia nervosa), and various medical manipulations and medications including general anaesthetics, antibiotics, antihistamines, and ironically antiarrhythmic agents. ${ }^{15} 16$ Acquired LQTS is common, with a population prevalence rate of up to $8 \% .{ }^{17}$ Because almost all cases of acquired LQTS are sporadic, genetic analysis of acquired LQTS has been lagging behind inherited LQTS. However, there has recently been increased interest in determining the genetic basis of acquired LQTS by studying genes causing inherited LQTS. ${ }^{18-21}$ We carried out a similar analysis in this study.

Voltage gated sodium channels are transmembrane proteins responsible for generating cardiac action potentials, and for rapid conduction of electrical signals through cardiac tissues. The cardiac sodium channel is a large protein of 2016 amino acids encoded by the SCN5A gene. ${ }^{22}$ The cardiac sodium channel consists of a pore forming $\alpha$-subunit composed of four homologous domains (I-IV), each containing six transmembrane segments $(\mathrm{S} 1-\mathrm{S} 6) .{ }^{22} \mathrm{SCN} 5 \mathrm{~A}$ is central to the genesis of cardiac arrhythmias and sudden death, and its mutations cause inherited LQTS, ${ }^{13}$ idiopathic ventricular fibrillation and Brugada syndrome, ${ }^{23}$ and cardiac conduction disease. $^{24}$ In this report, we have identified an SCN5A mutation, R1193Q (R/Q), in one of seven patients with acquired LQTS. Functional studies demonstrate that the electrophysiological severity of R/Q is nearly identical to two LQT3 mutations, N1325S (N/S) and Rl644H (R/H), which cause susceptibility to inherited LQTS.

\section{MATERIALS AND METHODS}

\section{Human genomic DNA samples}

Informed consent was obtained from study participants in accordance with standards established by local institutional review boards. Genomic DNA was prepared from whole blood

\section{Key points}

- Long QT syndrome (LQTS) is a cardiac disorder that causes syncope and sudden death from ventricular tachycardia torsade de pointes. Mutations in the cardiac sodium channel gene SCN5A cause the inherited type 3 LQTS (LQT3). LQTS can also be caused by drugs and other factors, known as acquired LQTS.

- In this study, we identified a missense mutation, $R 1193 Q$ or $3578 G \rightarrow A$ in SCN5A in one of seven patients with acquired LQTS.

- Mutant R1193Q SCN5A channels destabilise inactivation gating and generate a persistent, non-inactivating current that is expected to prolong the cardiac action potential duration, leading to LQTS. Single channel recording revealed that the molecular mechanism for the generation of the late persistent inward current is frequent, dispersed reopening of the channels.

- The biophysical defects of RI 193Q are nearly identical to two well characterised SCN5A mutations, N1325S and $\mathrm{R} 1644 \mathrm{H}$, which cause LQT3.

- These results strongly suggest that $R 1193 Q$ is a functional mutation that can increase susceptibility to LQTS.

- Notably, $0.2 \%$ of the general population carry the SCN5A mutation R1193Q, suggesting that this mutation may be an important risk factor to LQTS in the general population.

with the DNA Isolation kit for Mammalian Blood (Roche Diagnostic Co., Indianapolis, IN, USA).

The control population consists of $90.5 \%$ whites, 3.7\% African Americans, 0.8\% Hispanics, 0.4\% Asians, 0.4\% Native Americans, and $4.2 \%$ others.

Single strand conformation polymorphism (SSCP) and DNA sequencing analyses

PCR primers to amplify exons and intron-exon boundaries of SCN5A were as described previously. ${ }^{25}$ SSCP and DNA sequencing analyses were also carried out as described previously. ${ }^{522326}$

\section{Mutagenesis}

The mutation (R/Q) was introduced into the wild type SCN5A expression construct by site directed mutagenesis using the

Abbreviations: LQTS, long QT syndrome; ECG, electrocardiogram; $\mathrm{SSCP}$, single strand conformational analysis 
A

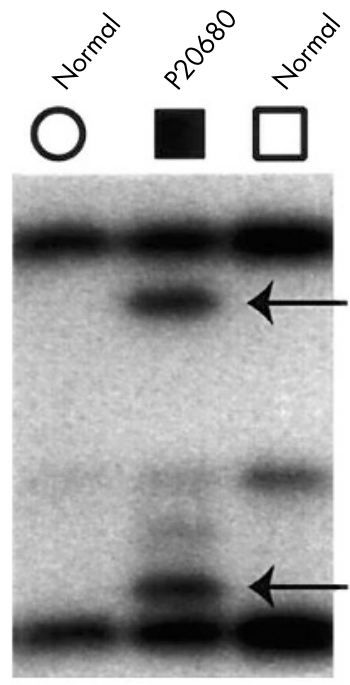

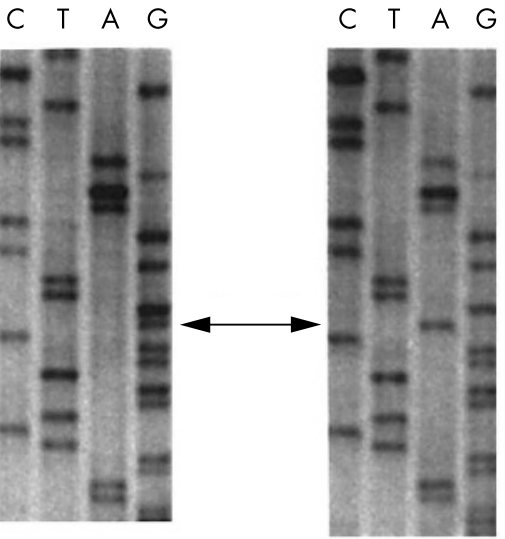

Normal
Figure 1 SCN5A R/Q missense mutation in a patient with acquired LQTS and ventricular tachyarrhythmias. (A) The results of SSCP analyses. The aberrant SSCP conformers are indicated by arrows. Sequence analyses of the normal (left) and aberrant conformers (right) revealed a $G \rightarrow A$ substitution (B), which results in substitution of arginine at codon 1193 by glutamine in the linker between homologous domains II and III (C). (D) Polymorphic ventricular tachycardia recorded in patient P20680 by Holter monitoring. Atrial fibrilliation (AF) was also detected in patient P20680, but it remains to be determined whether SCN5A mutation R1193Q is the cause of $A F$ in this patient.

C Normal GGG AAG GTC TGG TGG CGG TTG CGC AAg ACC TGC $\begin{array}{llllllllllll}\mathrm{G} & \mathrm{K} & \mathrm{V} & \mathrm{W} & \mathrm{W} & R & \mathrm{~L} & \mathrm{R} & \mathrm{K} & \mathrm{T} & \mathrm{C}\end{array}$ R1193Q

P20680 $\nabla$ GGG AAg GTC TGG TGG CAG TTG CGC AAG ACC TGC

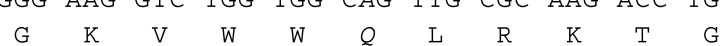

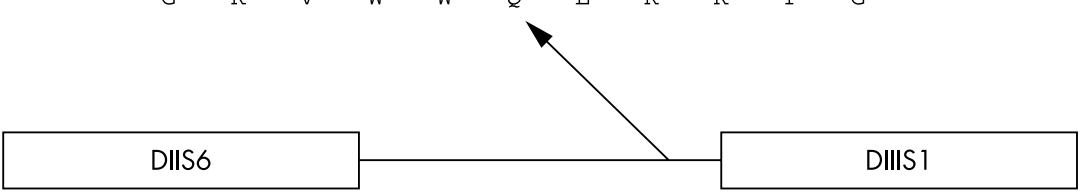

D

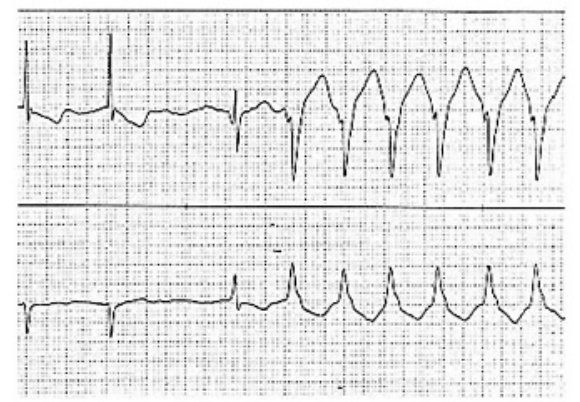

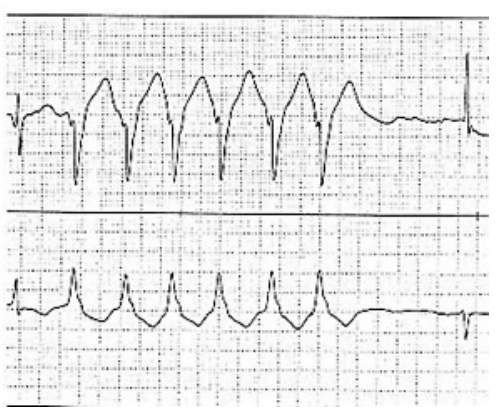

mega-primer PCR based method, ${ }^{27}$ and verified by DNA sequencing.

\section{Electrophysiology and data analysis}

Electrophysiological recording was performed in human embryonic kidney (HEK-293) cells transiently transfected with hHl cDNA (no H558R or Q1077del variants) as described previously ${ }^{28} 29$ and in Xenopus oocytes injected with in vitro transcribed cRNA as described previously. ${ }^{30}$

\section{RESULTS}

\section{Identification of SCN5A mutation $R / Q$ in a patient} with acquired LQTS

The complete genomic structure of SCN5A has been determined previously, ${ }^{25}$ and intronic primers are available for amplifying all exons and exon-intron boundaries by PCR. Using SSCP analysis, we identified an anomalous band in patient P20680 who was affected with acquired LQTS (fig 1A). DNA sequence analysis of the normal and the aberrant SSCP conformers revealed that the abnormal SSCP conformer contained a single base substitution ( $G$ to $A$ transition; $3578 \mathrm{G} \rightarrow \mathrm{A}$ ) at the second nucleotide of codon R1193 of SCN5A (fig 1B), which resulted in a nonconservative replacement of arginine with glutamine (R/Q) between transmembrane domains II and III of the cardiac sodium channel (fig lC). We also screened patient P20680 for mutations in other known LQTS genes, but found none (data not shown). As the index patient P20680 is an 82 year old single male without living family members, we were unable to determine whether other family members carry the $\mathrm{R} / \mathrm{Q}$ mutation.

The index patient P20680 is a white male, and developed LQTS (QTC $=490-570 \mathrm{~ms}$ ) with administration of D-sotalol, whereas the baseline QTc before drug treatment was $442 \mathrm{~ms}$. 
A WT

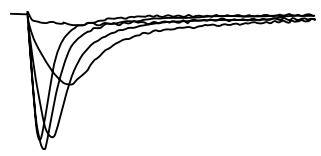

B $R / Q$
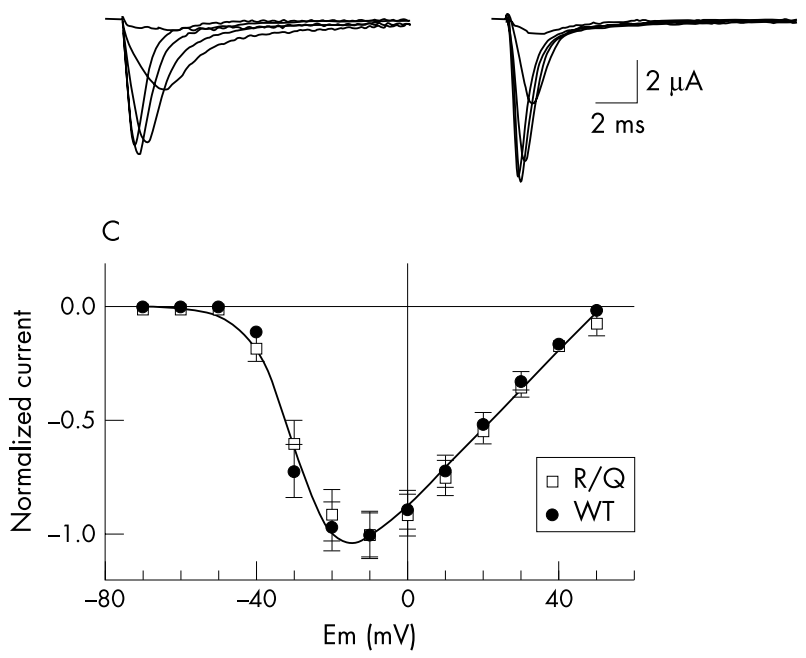

D
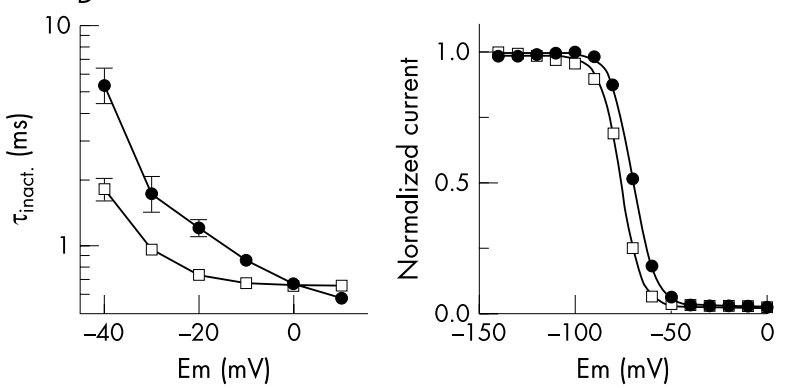

Figure 2 Electrophysiological characterisation of normal $(A)$ and $R / Q$ mutant (B) $\mathrm{Na}^{+}$channels. Whole cell currents (A-B) were obtained by intracellular microelectrode voltage clamp. Each panel shows superimposed current traces evoked by test pulses of -40 to $0 \mathrm{mV}$ (10 $\mathrm{mV}$ increments) from a holding potential of $-100 \mathrm{mV}$. Linear leakage and capacitation were corrected by online (P/4) subtraction; residual transients were blanked. Peak test pulse current amplitude (normalised to maximum current, mean (SEM)) was plotted as a function of test pulse amplitude for wild type (WT; filled circles) and R/Q (open squares) channels. The data were fitted to Boltzmann distributions of the form: $I=G_{\text {max }}\left(V-V_{\text {rev }}\right)\left(1-\left(1 /\left(1+\exp \left(\left(V-V_{0.5}\right) / k\right)\right)\right)\right)$; where $\mathrm{G}_{\text {max }}=$ scale factor, $\mathrm{V}=$ test pulse amplitude, $V_{\text {rev }}=$ reversal potential $\mathrm{V}_{0.5}=$ midpoint potential, and $\mathrm{k}=$ slope factor. The decay phase of current evoked by test pulses of -40 to $+40 \mathrm{mV}$ was fitted to monoexponential decay functions and the time constant $\left(\tau_{\text {inact }}\right)$ was plotted semi-logarithmically $v$ test pulse potential (D). The voltage dependence of steady state inactivation was determined using a standard two pulse protocol in which a $500 \mathrm{~ms}$ variable amplitude conditioning pulse was followed by a $15 \mathrm{~ms}$ fixed amplitude $(-10 \mathrm{mV})$ test potential. Test pulse current amplitude (normalised to maximum current) was plotted $v$ conditioning pulse amplitude to assess the fraction of non-inactivated channels (E). The data were fitted to Boltzmann distributions (smooth curves) of the form: $I=\left(1+\exp \left(\left(V-V_{0.5}\right) / k\right)\right)^{-1}$ where $V=$ conditioning pulse amplitude, $\mathrm{V}_{0.5}=$ midpoint potential, and $\mathrm{k}=$ slope factor. Pooled data (C-E) are plotted as mean (SEM), $n=8$, and 18, respectively for WT and $R / Q$.

Two days after D-sotalol was stopped, a Holter report detected monomorphic ventricular tachycardia (VT) (fig 1D). No polymorphic VT or torsade de pointes was detected. The patient was then started on quinidine; this treatment also produced dramatic QT prolongation $(\mathrm{QTc}=508 \mathrm{~ms})$.

High population prevalence rate of SCN5A R/Q

To test whether SCN5A R/Q is present in the general population, SSCP analysis with the primers used to identify the R/Q mutation was performed using DNA samples from 2087 randomly selected individuals, a predominantly white population. Anomalous SSCP conformers were identified in 4 of 2087 individuals $(0.2 \%)$. We sequenced these abnormal conformers and found that they contained the R/Q mutation. These data suggest that the average prevalence rate of the $\mathrm{R} / \mathrm{Q}$ mutation in the general population can reach up to $0.2 \%$.

Among the four carriers with SCN5A R/Q from the general population, we were able to obtain ECGs from only two, who had a QTc of $421 \mathrm{~ms}$ and $430 \mathrm{~ms}$, respectively. It would be useful to determine whether the QTc of these carriers with SCN5A R/Q would become more prolonged by quinidine and other drugs, but such studies raise ethical issues.

\section{Establishment of $R / Q$ as a functional mutation}

The $\mathrm{R} / \mathrm{Q}$ mutation results in the neutralisation of a highly conserved, positively charged side chain within the intracellular domain of the channel protein. Previous studies have shown that similar substitutions are responsible for altered channel gating. ${ }^{3031}$ To determine whether SCN5A R/Q is a functional mutation, we used electrophysiology to characterise it by heterologous expression in Xenopus oocytes and in mammalian HEK293 cells.
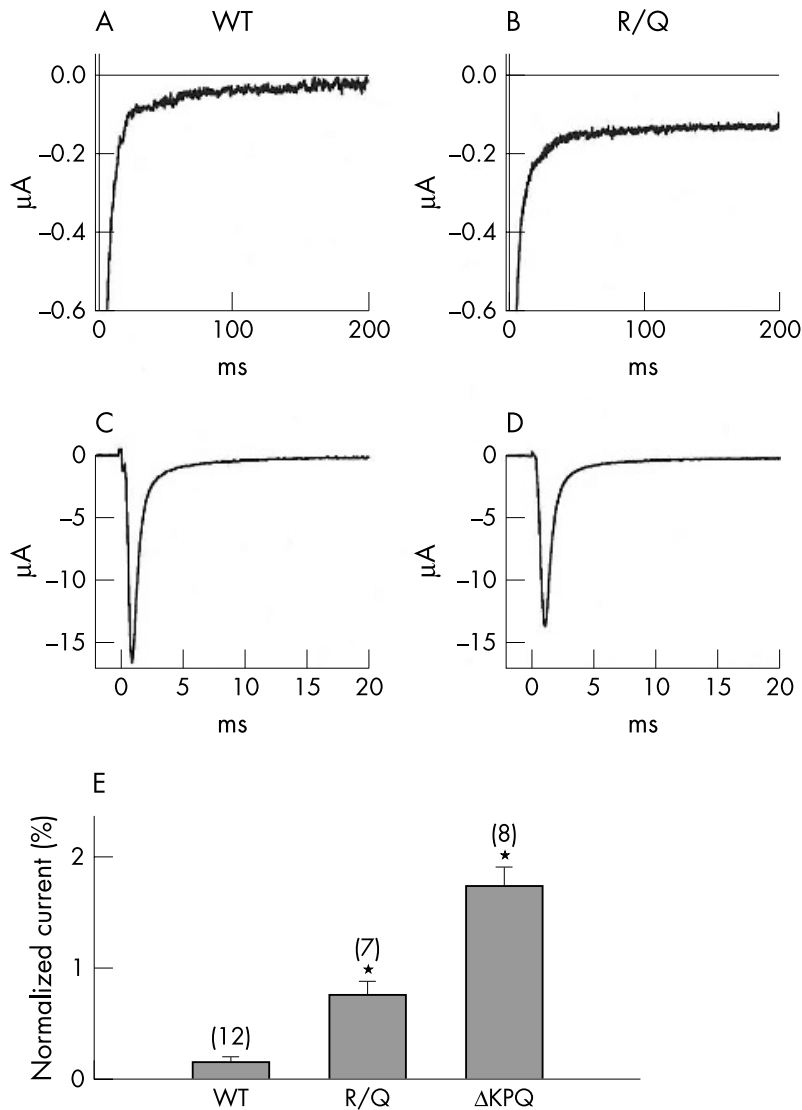

Figure 3 Late $\mathrm{Na}^{+}$current in normal and mutant channels. Records of inward $\mathrm{Na}^{+}$current (at a $-10 \mathrm{mV}$ test potential) were obtained by subtracting records obtained after application of $200 \mathrm{mmol} / \mathrm{I}$ TTX from total current before TTX. Typical difference currents obtained in this way are illustrated for WT ( $A$ and $C$ ) and $R / Q$ mutant ( $B$ and $D)$ channels. High amplification ( $A$ and $B$ ) revealed significant amounts of persistent late current that represents a small fraction $(<1 \%)$ of the peak current ( $C$ and $D$, note the change in amplification and time base) only in the mutant channels (B). Panel $C$ presents the pooled data of each channel group (WT and R/Q), compared with $\triangle K P Q .{ }^{30}$ Persistent current (normalised to peak currents and expressed as mean (SEM) per cent) was taken as the average current over the time interval 180-200 ms (except for $\triangle K P Q$, measured at $300 \mathrm{~ms}$ ). The number in parentheses is the number of oocytes tested. *Indicates significant difference between means ( $p<0.05$, two tailed Student's $t$ test) compared with WT. 
WT

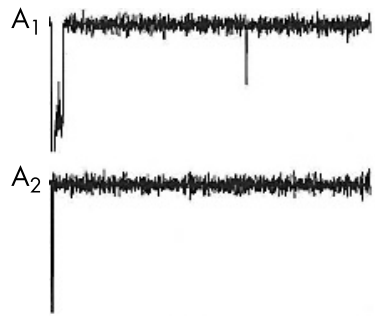

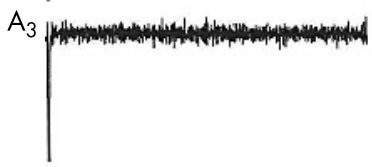

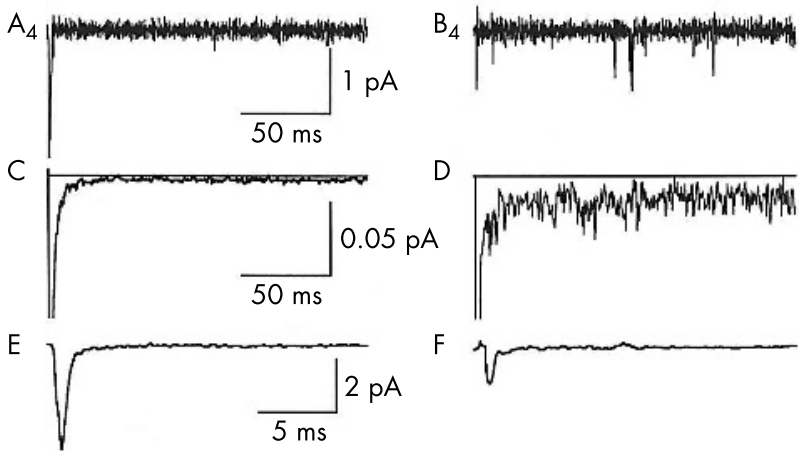

Figure 4 Single channel basis of persistent current in $R / Q$ mutant channels. Current records were obtained using extracellular patch clamp recording in the cell-attached mode. (A, C, E) Wild type (WT); (B, D, F) $R / Q$. Consecutive current traces $(A 1-4 ; B 1-4)$ were evoked by a test potential of $0 \mathrm{mV}$ from a holding potential of $-100 \mathrm{mV}$ (preceded by a $100 \mathrm{~ms}$ prepulse to $-140 \mathrm{mV}$ to remove resting inactivation) at a frequency of 1 pulse/s. Channel openings are downward deflections in the current traces. The start of the test pulse is coincident with the residual uncorrected capacitative current. Panels $C$ and $D$ show ensemble averages of 128 records, plotted at a high amplification to emphasise the persistent current observed in R/Q channels (D). Peak currents were off the scale. Panels $E$ and $F$ show fast time base, low amplification plots of the ensemble averages to facilitate comparison of peak currents. Recording bandwidth was $2 \mathrm{kHz}$. Similar results were obtained in replicate experiments from $11 \mathrm{WT}$ and $7 \mathrm{R} / \mathrm{Q}$ patches.

Fig 2A, B shows representative intracellular microelectrode voltage clamp records for either wild type (A) or R/Q (B) channels. Current-voltage families were evoked by test pulses of -50 to $+40 \mathrm{mV}$ ( $10 \mathrm{mV}$ increments) from a holding potential of $-100 \mathrm{mV}$. A comparison of the peak curren$\mathrm{t}$-voltage relationships in the two channels (fig 2C) showed that the voltage dependence of activation was nearly unchanged by the R/Q mutation (open squares). Both sets of data accurately fitted to Boltzmann expressions (smooth curves) with a midpoint potential of $-29 \mathrm{mV}$ and slope factor of $5.7 \mathrm{mV}$. The most striking feature of R/Q channels was that $\mathrm{Na}^{+}$currents at moderately depolarising test potentials $(-40$ to $0 \mathrm{mV}$ ) decayed more rapidly than the normal time course (fig 2A, B). As the onset of inactivation is the major contributor to the decay of $\mathrm{Na}^{+}$current at test potentials more positive than $-40 \mathrm{mV},{ }^{32}$ we fitted the time course to a mono-exponential decay function and plotted the time constant of inactivation ( $\tau_{\text {inact }}, \log$ scale $)$ as a function of test potential (fig 2D). At negative test potentials, the onset of inactivation was significantly faster in $\mathrm{R} / \mathrm{Q}$ (open squares) than wild type (filled circles) channels (for instance, a threefold acceleration of R/Q time constants was obtained at a test potential of $-40 \mathrm{mV}$ ). The voltage dependence of steady state inactivation (fig $2 \mathrm{E}$ ) was consistent with the observed kinetic changes; compared with wild type channels,
R/Q channels displayed a negative shift of the steady state inactivation curve. When fitted to Boltzmann functions (smooth curves) a midpoint potential of $-70 \mathrm{mV}$ (slope factor $5.5 \mathrm{mV}$ ) was obtained in wild type, and $-76 \mathrm{mV}$ (slope factor $5.3 \mathrm{mV}$ ) in R/Q (fig 2E).

Mutations that produce persistent non-inactivating $\mathrm{Na}^{+}$ currents cause LQT3. ${ }^{31}$ We tested for the presence of such currents at the whole cell level by a tetrodotoxin (TTX) subtraction method..$^{33}$ Examination of the late phase (time $>30 \mathrm{~ms}$ ) of current at high amplification (peak current off the scale) revealed negligible inward $\mathrm{Na}^{+}$current in wild type channels (A) but substantial late, non-inactivating current in $\mathrm{R} / \mathrm{Q}$ channels. The increase in persistent current in mutant channels was not due simply to an over-expression of $\mathrm{R} / \mathrm{Q}$ channels, as peak WT (fig 3C) current was larger than that of $\mathrm{R} / \mathrm{Q}$ (fig 3D), presumably because of variations in expression level. We compared the relative amounts of persistent current by normalising to peak current in each cell (fig 3E). Wild type cells produced negligible levels of persistent current, but R/Q mutants produced substantial amounts of persistent current that were comparable to that produced by other LQT3 mutants, $\mathrm{R} / \mathrm{H}$ and $\mathrm{N} / \mathrm{S}$, and about half of that produced by the most severe LQT3 mutant, $\triangle \mathrm{KPQ} .^{30}$ Similar results were obtained in a mammalian expression system (transiently transfected HEK-293 cells). Test pulses of $300 \mathrm{~ms}$ duration evoked a persistent inward current (mean (SEM), $\mathrm{n}=10$ cells) of $-44.3(7.2) \mathrm{pA}$ in cells that expressed R/Q. In contrast, the amplitude of persistent currents in cells that expressed wild type channels was $-17.4(10.0) \mathrm{pA}(\mathrm{n}=12)$. When normalised to peak current amplitudes, the level of persistent current in R/Q mutant channels was $1.29(0.33) \%$ of the peak amplitude $v 0.31(0.30) \%$ in wild type channels. These results suggest that the $S C N 5 A \mathrm{R} / \mathrm{Q}$ is a functional mutation, and that, similar to the well characterised R/H and N/S LQTS mutations, R/Q is expected to increase the risk of LQTS.
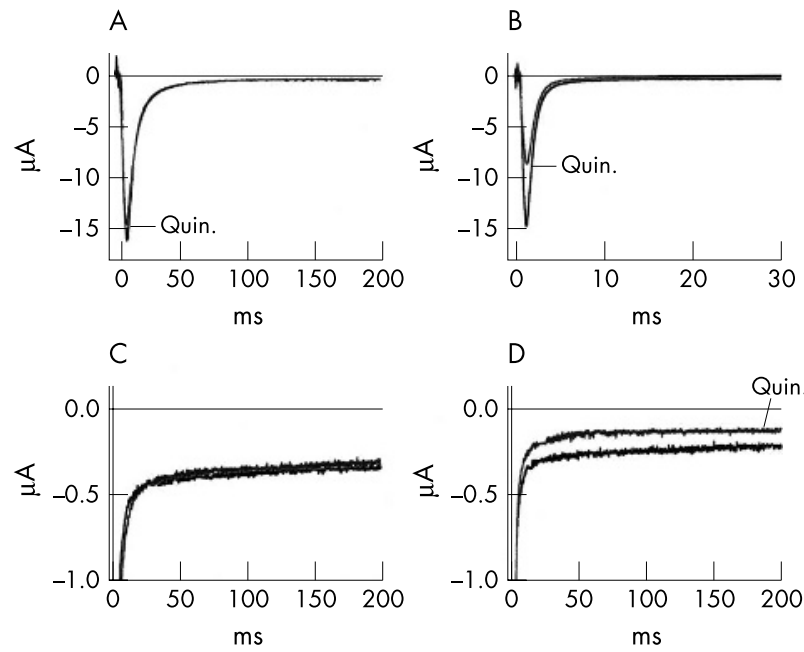

Figure 5 Effect of quinidine on $R / Q$ channels. (A-B) Representative records of peak currents evoked by test potentials of $-10 \mathrm{mV}$ from a holding potential of $-100 \mathrm{mV}$ in the presence and absence of $50 \mu \mathrm{mol} / \mathrm{I}$ quinidine. (A) The effect of drug on resting channels held at $-100 \mathrm{mV}$ for 3 minutes prior to the test pulse. (B) Maximum blocking effect of activated channels. A conditioning train of 200 brief pulses $15 \mathrm{~ms}$ duration, $-10 \mathrm{mV}$ amplitude, $10 \mathrm{~Hz}$. repetition rate) preceding the test pulse $(50 \mathrm{~ms}$ interval at $-100 \mathrm{mV})$ allowed use dependent accumulation of channels in the activated, drug bound state. ${ }^{34}$ (C-D) Late currents evoked by $200 \mathrm{~ms}$ test pulses to $-100 \mathrm{mV}$ before and after equilibration in $50 \mu \mathrm{mol} / \mathrm{I}$ quinidine in the same experiment as $A$ and $B$. Records in panel $C$ and $D$ respectively, were obtained in the absence and presence of the conditioning train described above. 
We have shown previously that dispersed reopenings are responsible for nearly all of the persistent current in the LQT3 mutants $\mathrm{R} / \mathrm{H}$ and $\mathrm{N} / \mathrm{S}$, and about half of that in $\Delta \mathrm{KPQ}{ }^{30}$ The R/Q mutant associated with acquired LQTS showed a pattern similar to the R/H and N/S mutants of inherited LQTS (fig 4). Thus, in multi-channel, cell attached patches during maximum activation, wild type channels rarely reopened after the initial transient current (off scale) of synchronously active channels had subsided. An example of a rare reopening is shown in trace $A_{1}$. By contrast, $R / Q$ channels (fig $4 B_{1}-B_{4}$ ) generated frequent, dispersed reopenings similar to those observed previously in the LQT3 mutants. In R/Q channels, as in wild type (and in the previously described $\mathrm{R} / \mathrm{H}$ and N/S mutants), prolonged bursting such as that associated with the $\triangle \mathrm{KPQ}$ mutation was extremely rare.

Because acquired LQTS in this patient was precipitated by quinidine, a drug that blocks both $\mathrm{Na}^{+}$and $\mathrm{K}^{+}$channels, we were interested to know whether the late currents generated by $\mathrm{R} / \mathrm{Q}$ mutant channels were affected by quinidine treatment. Quinidine blocks $\mathrm{Na}^{+}$channels in a use dependent manner such that repetitive brief depolarisations that maximally activate channels produce the greatest blocking effect. ${ }^{34}$ As shown in fig 5A, quinidine at $50 \mathrm{~mol} / \mathrm{l}$ had little effect on peak $\mathrm{Na}^{+}$conductance in resting $\mathrm{R} / \mathrm{Q}$ mutant channels (that is, in channels maintained for several minutes at the holding potential of $-120 \mathrm{mV}$ without repetitive activation). Average blocking effect was $7.1(1.5) \%(n=7)$. Similar results were obtained in wild type channels (not illustrated), with an average block of $6.3(0.6) \%(n=7)$. Most importantly, however, quinidine was ineffective in blocking the late, residual current (fig 5C) in the absence of a conditioning train even though the test pulse was long enough to produce $>90 \%$ inactivation of the peak current. Average late current blocking effect under this condition was $7.7(2.2) \%(n=6)$. However, application of a conditioning train of pulses that allowed accumulation of drug bound open channels caused a substantial blockade of peak R/Q currents (fig 5B); the test pulse current was preceded by a conditioning train of 200 brief activating pulses of $5 \mathrm{~ms}$ duration and $-10 \mathrm{mV}$ amplitude, delivered at a repetition rate of $10 \mathrm{~Hz}$ ). Average blocking effect of peak current was $40.0(3.0) \%(n=8)$. Under this stimulus regimen, late current observed during a long depolarising test pulse was suppressed to the same extent as the reduction in peak current; the average blocking effect of late current was 44.1 $(11.6) \%(n=5)$.

\section{DISCUSSION}

In this study, we identified a missense mutation R/Q in the cardiac sodium channel gene SCN5A in one of seven patients with acquired LQTS. Electrophysiological characterisation revealed that $\mathrm{R} / \mathrm{Q}$ altered the function of the cardiac sodium channel (fig 2-5), which clearly demonstrates that SCN5A R/ $\mathrm{Q}$ is a functional mutation. It is important to note that the biophysical phenotype of the mutant R/Q channels markedly resembles that of well established mutations $(\mathrm{N} / \mathrm{S}$ and $\mathrm{R} / \mathrm{H}$ in SCN5A) causing inherited LQTS. All generate a similar number of late inward currents via dispersed reopening, a well established cause of type 3 LQTS. ${ }^{30}{ }^{31}$ Expression of the human SCN5A N/S mutant channel in the mouse heart leads to generation of late persistent inward current in myocytes, and development of LQTS, ventricular arrhythmias, and sudden death in transgenic mice. ${ }^{35}$ Thus, the SCN5A R/Q mutation is expected to cause susceptibility to LQTS. Furthermore, the combination of a genetic mutation and external factors such as D-sotalol and quinidine may unmask the underlying genetic defect, resulting in the development of LQTS and cardiac arrhythmias. This may explain the finding that the QTc for the index patient with the SCN5A R/Q mutation increased dramatically from $442 \mathrm{~ms}$ to $570 \mathrm{~ms}$ with D-sotalol and to $508 \mathrm{~ms}$ with administration of quinidine. An echocardiograph report for the index patient revealed moderate left ventricle enlargement, moderate global hypokinesis, and mild tricuspid and mitral regurgitation, which may also act as external factors that help precipitate the development of acquired LQTS. Our study is consistent with the findings from two other reports. Piippo et al recently showed that QTC for a carrier of the V1667I SCN5A mutation increased from $460 \mathrm{~ms}$ to $580 \mathrm{~ms}$ with administration of halofantrine. ${ }^{20}$ An elderly Japanese woman with acquired LQTS and acquired TdP carried an SCN5A mutation, L1825P. ${ }^{36}$ However, it should be noted that the R/Q mutation, instead of acting as an allelic variant creating a substrate at risk for acquired LQTS, may represent an incompletely penetrant LQTS mutation.

The index patient in this study also carries another SCN5A polymorphism, H558R, which is present in $20-30 \%$ of the population; however, lack of family members meant we could not determine whether H558R is in the cis or trans localisation with Rl193R. The patient does not harbour the common variant Q1077del. ${ }^{37}$ The variant H558R has been shown to modulate the effects of other SCN5A mutations including M1766L and T512I. ${ }^{37-39}$ Future studies may determine whether H558R has any impact on the R1193R mutation.

In a recent publication, Takahata et al..$^{40}$ described the identification of the $\mathrm{R} / \mathrm{Q}$ mutation in one of 6 Japanese patients with Brugada syndrome, and one of 48 normal controls. As shown in fig 2, the R/Q channels inactivate more rapidly than wild type (fig $2 \mathrm{~A}, \mathrm{~B}$ ), and the onset of inactivation was three times faster in $\mathrm{R} / \mathrm{Q}$ than in wild type channels (fig 2D). These effects are expected to decrease the availability of sodium conductance, which may account for the possibility that R/Q may also be associated with Brugada syndrome. As previously reported, a single mutation, for example, the 1795insD mutation in SCN5A, can be associated with both Brugada and long QT syndromes. ${ }^{41}{ }^{42}$

A de novo $\mathrm{Na}^{+}$channel missense mutation (R1623Q) associated with severe LQTS has been identified. ${ }^{43}$ This substitution is at an extracellular position in domain IV of the $\alpha$-subunit. The highly conserved $\operatorname{Arg}^{16}{ }^{23}$ corresponds in the human skeletal muscle $\mathrm{Na}^{+}$channel to the site of paramyotonia congenita mutations $(\mathrm{R} 1448 \mathrm{H}, \mathrm{C}){ }^{44}$ In both cardiac $^{45}{ }^{46}$ and skeletal muscle ${ }^{47}$ channels, mutations at this position slow the rate of inactivation and prolong the single channel open time. In contrast, the highly conserved Rl193 described here is located on the intracellular side of the channel in the linker segment between homologous transmembrane domains II and III. The R/Q mutation does not slow the rate of inactivation (fig 2), but rather produces a persistent late current that originates as dispersed reopenings (fig 4). Therefore, unlike the extracellular R/Q mutation, which slows the onset of inactivation, the intracellular $\mathrm{R} / \mathrm{Q}$ mutation appears to reduce the stability of the inactivated state, allowing brief returns from inactivated to open states in a manner similar to that observed in other intracellular LQTS mutations.

R1193 is located in the linker between domains II and III, several residues upstream from the proposed boundary of transmembrane segment DIIIS1. This residue is conserved among mammalian $\mathrm{Na}^{+}$channel isoforms, but the functional importance of the linker is under active investigation. In a previous study of rat brain $\mathrm{Na}^{+}$channels, Stühmer et $a l^{48}$ showed that deletion of a large segment of this linker or the introduction of a cut did not cause gross changes in macroscopic gating characteristics. Therefore, this region is unlikely to be directly involved in gating. However, in agreement with our data (fig 2) the voltage dependence of steady state activation was unchanged while inactivation was 
shifted by about $-6 \mathrm{mV}$. The low amplitude persistent currents that we observed would probably have gone undetected in their experiments because TTX subtraction and single channel recording were not performed. Our results suggest that R1193, together with other residues located at intracellular sites, including LQT3 loci in domains III and IV of the cardiac $\mathrm{Na}^{+}$channel ${ }^{30}$ as well as several myotonia loci in domains III and IV of the skeletal muscle $\mathrm{Na}^{+}$channel, ${ }^{49}{ }^{50}$ influence the stability of the inactivated state as evidenced by mutation induced generation of dispersed reopenings. The mechanism whereby amino acid substitutions influence stability is unknown, but for R/Q substitution both a charge neutralisation and a reduction in volume might have an indirect effect on inactivation either by electrostatic or steric mechanisms.

As the patient with acquired LQTS in this study developed LQTS with administration of quinidine, a well known $\mathrm{Na}^{+}$ and $\mathrm{K}^{+}$channel blocker, we were interested to know whether the late currents generated by $\mathrm{R} / \mathrm{Q}$ mutant channels were resistant to quinidine blockade. We found that late current could only be blocked after high frequency conditioning stimulation. This result is consistent with the notion that quinidine primarily blocks channels in the open rather than inactivated or resting states of the channel..$^{34}$ By contrast, the conditions that trigger arrhythmia in patients include bradycardia and long pauses in heart rhythm. Therefore, the ability of quinidine ability to block $\mathrm{Na}^{+}$channels is unlikely to be responsible for arrhythmias associated with acquired LQTS. A more likely explanation is that quinidine blockade of outward $\mathrm{K}^{+}$current unmasks the proarrhythmic action of the persistent current in the mutant $\mathrm{Na}^{+}$channels.

Our results show that quinidine blockade of late, persistent currents was no more effective than blockade of early, transient $\mathrm{Na}^{+}$currents. Thus, unlike class Ib antiarrhythmic drugs such as mexiletine and lidocaine, which preferentially block inactivated channels ${ }^{51}$ and selectively suppress late currents in LQT3 mutant channels, ${ }^{30} 4152$ quinidine would not be expected to ameliorate $L Q T 3$ defects in gating. Whether the phenotype of the $\mathrm{R} / \mathrm{Q}$ mutation can be corrected by lidocaine or other drugs that stabilise the inactivated state remains to be determined.

In conclusion, we have identified a common mutation $\mathrm{R} / \mathrm{Q}$ in SCN5A. Our electrophysiological studies establish R/Q as a functional mutation that can cause susceptibility to cardiac arrhythmias. The common occurrence of the R/Q SCN5A mutation underlines the importance of this mutation as a risk factor for LQTS and ventricular arrhythmia in the general population.

\section{ACKNOWLEDGEMENTS}

This work was supported by NIH R01 HL66251 and a grant-in-aid from the American Heart Association Ohio-Affiliate (Q Wang) Bristol-Myers Squibb (M T Keating), and a grant in aid from the American Heart Association with funds contributed in part by the AHA, Northeast Ohio Affiliate (G E Kirsch). We thank J Poruban for proofreading and the members of the Wang Laboratory for help with preparation of control human genomic DNA.

\section{Authors' affiliations \\ Q Wang, S Chen, Q Chen, A A Timur, Department of Molecular} Cardiology, Lerner Research Institute, and Center for Cardiovascular Genetics, Department of Cardiovascular Medicine, The Cleveland Clinic Foundation, Department of Molecular Medicine, Cleveland Clinic Lerner College of Medicine of Case Western Reserve University, Cleveland, $\mathrm{OH}$ 44195, USA

Q Chen, Cole Eye Institute, The Cleveland Clinic Foundation, Cleveland, $\mathrm{OH} 44195$, USA

X Wan, G E Kirsch, Department of Physiology and Biophysics, Case Western Reserve University MetroHealth Campus, Cleveland, $\mathrm{OH}$ 44109, USA
S Jiaxiang, University of Utah Health Sciences Center, Salt Lake City, UT 84112 , USA

G A Hoeltge, Department of Clinical Pathology, The Cleveland Clinic Foundation, Cleveland, $\mathrm{OH}$ 44195, USA

M T Keating, Department of Cell Biology and Howard Hughes Medical Institute, Harvard Medical School, Boston, MA 02115, USA

G E Kirsch, ChanTest Inc, and Department of Physiology and Biophysics, Case Western Reserve University, Cleveland, OH 44128, USA

Conflicts of interest: none declared

Correspondence to: Dr Q Wang, Director, Center for Cardiovascular Genetics, ND4-38, The Cleveland Clinic Foundation, 9500 Euclid Avenue, Cleveland, OH 44190, USA; wangq2@ccf.org or Dr G E Kirsch, ChanTest Inc, 14656 Neo Parkway, Cleveland, Ohio 44128, USA; gkirsch@chantest.com

Revised version received 6 October 2003 Accepted for publication 8 October 2003

\section{REFERENCES}

1 Schwartz PJ, Periti M, Malliani A. The long Q-T syndrome. Am Heart J 1975;89:378-90

2 Schwartz PJ, Locati EH, Napolitano C, Priori SG. The long QT syndrome. In: Zipes D, Jalife J, eds. Cardiac electrophysiology: from cell to bedside. Philadelphia: WB Saunders, 1996:788-811.

3 Vincent GM. The molecular genetics of the long QT syndrome: genes causing fainting and sudden death. Annu Rev Med 1998;49:263-74.

4 Wang Q, Pyeritz RE, Seidman C, Basson C. Genetic studies of myocardial and vascular disease. In: Topol EJ, ed. Textbook of cardiovascular medicine. Philadelphia, PA: Lippincott Williams \& Wilkins, 2002:1967-89.

5 Wang Q, Curran ME, Splawski I, Burn TC, Millholland JM, VanRaay TJ, Shen J, Timothy KW, Vincent GM, de Jager T, Schwartz PJ, Toubin JA, Moss AJ, Atkinson DL, Landes GM, Connors TD, Keating MT. Positional cloning of a novel potassium channel gene: KVLQT1 mutations cause cardiac arrhythmias. Nat Genet 1996;12:17-23.

6 Neyroud N, Tesson F, Denjoy I, Leibovici M, Donger C, Barhanin J, Faure S, Gary F, Coumel P, Petit C, Schwartz K, Guicheney P. A novel mutation in the potassium channel gene KVLQT1 causes the Jervell and Lange-Nielsen cardioauditory syndrome. Nat Genet 1997;15:186-9.

7 Splawski I, Timothy KW, Vincent GM, Atkinson DL, Keating MT. Molecular basis of the long-QT syndrome associated with deafness. N Engl J Med 1997;336:1562-7.

8 Curran ME, Splawski I, Timothy KW, Vincent GM, Green ED, Keating MT. A molecular basis for cardiac arrhythmia: HERG mutations cause long QT syndrome. Cell 1995;80:795-803.

9 Schulze-Bahr E, Wang Q, Wedekind H, Haverkamp W, Chen Q, Sun Y, Rubie C, Hordt M, Towbin JA, Borggrefe M, Assmann G, Qu X, Somberg JC, Breithardt G, Oberti C, Funke H. KCNE1 mutations cause Jervell and LangeNielsen syndrome. Nat Genet 1997;17:267-8.

10 Splawski I, Tristani-Firouzi M, Lehmann MH, Sanguinetti MC, Keating MT. Mutations in the hminK gene cause long QT syndrome and suppress IKs function. Nat Genet 1997;17:338-40.

11 Abbott GW, Sesti F, Splawski I, Buck ME, Lehmann MH, Timothy KW, Keating MT, Goldstein SA. MiRPI forms IKr potassium channels with HERG and is associated with cardiac arrhythmia. Cell 1999;97:175-87.

12 Wang Q, Shen J, Li Z, Timothy K, Vincent GM, Priori SG, Schwartz PJ, Keating MT. Cardiac sodium channel mutations in patients with long QT syndrome, an inherited cardiac arrhythmia. Hum Mol Genet 1995;4:1603-7.

13 Wang Q, Shen J, Splawski I, Atkinson D, Li Z, Robinson JL, Moss AJ, Towbin JA, Keating MT. SCN5A mutations associated with an inherited cardiac arrhythmia, long QT syndrome. Cell 1995;80:805-11.

14 Mohler PJ, Schott JJ, Gramolini AO, Dilly KW, Guatimosim S, duBell WH, Song LS, Haurogne K, Kyndt F, Ali ME, Rogers TB, Lederer WJ, Escande D, Le Marec H, Bennett V. Ankyrin-B mutation causes type 4 long-QT cardiac arrhythmia and sudden cardiac death. Nature 2003;421:634-9.

15 Roden DM. Torsade de pointes. Clin Cardiol 1993;16:683-6.

16 Roden DM, Lazzara R, Rosen M, Schwartz PJ, Towbin J, Vincent GM. Multiple mechanisms in the long-QT syndrome. Current knowledge, gaps, and future directions. The SADS Foundation Task Force on LQTS. Circulation 1996:94:1996-2012

17 Jackman WM, Friday KJ, Anderson JL, Aliot EM, Clark M, Lazzara R. The long QT syndromes: a critical review, new clinical observations and a unifying hypothesis. Prog Cardiovasc Dis 1988;31:115-72.

18 Sesti F, Abbott GW, Wei J, Murray KT, Saksena S, Schwartz PJ, Priori SG, Roden DM, George AL Jr, Goldstein SA. A common polymorphism associated with antibiotic-induced cardiac arrhythmia. Proc Natl Acad Sci USA 2000;97:10613-18.

19 Napolitano C, Schwartz PJ, Brown AM, Ronchetti E, Bianchi L, Pinnavaia A, Acquaro G, Priori SG. Evidence for a cardiac ion channel mutation underlying drug-induced QT prolongation and life-threatening arrhythmias. J Cardiovasc Electrophysiol 2000;11:691-6

20 Piippo K, Holmstrom S, Swan H, Viitasalo M, Raatikka M, Toivonen L, Kontula K. Effect of the antimalarial drug halofantrine in the long QT syndrome due to a mutation of the cardiac sodium channel gene SCN5A. Am J Cardiol 2001;87:909-11. 
21 Yang $P$, Kanki $H$, Drolet $B$, Yang $T$, Wei J, Viswanathan $P C$, Hohnloser $\mathrm{SH}$ Shimizu W, Schwartz PJ, Stanton M, Murray KT, Norris K, George AL Jr, Roden DM. Allelic variants in long-QT disease genes in patients with drugassociated torsades de pointes. Circulation 2002;105:1943-8.

22 Gellens ME, George AL Jr, Chen LQ, Chahine M, Horn R, Barchi RL, Kallen RG. Primary structure and functional expression of the human cardiac tetrodotoxin-insensitive voltage-dependent sodium channel. Proc Natl Acad Sci USA 1992;89:554-8.

23 Chen Q, Kirsch GE, Zhang D, Brugada R, Brugada J, Brugada P, Potenza D, Moya A, Borggrefe M, Breithardt G, Ortiz-Lopez R, Wang Z, Antzelevitch C, O'Brien RE, Schulze-Bahr E, Keating MT, Towbin JA, Wang Q. Genetic basis and molecular mechanism for idiopathic ventricular fibrillation. Nature 1998;392:293-6

24 Tan HL, Bink-Boelkens MT, Bezzina CR, Viswanathan PC, Beaufort-Krol GC, van Tintelen PJ, van den Berg MP, Wilde AA, Balser JR. A sodium-channel mutation causes isolated cardiac conduction disease. Nature 2001;409: 1047.

25 Wang Q, Li Z, Shen J, Keating MT. Genomic organization of the human SCN5A gene encoding the cardiac sodium channel. Genomics 1996;34:9-16.

26 Chen S, Chung MK, Martin D, Rozich R, Tchou PJ, Wang Q. SNP S1 103 Y in the cardiac sodium channel gene SCN5A is associated with cardiac arrhythmias and sudden death in a white family. J Med Genet 2002;39:913-15.

27 Sarkar G, Sommer SS. The "megaprimer" method of site-directed mutagenesis. Biotechniques 1990;8:404-7.

28 Wan X, Wang Q, Kirsch GE. Functional suppression of sodium channels by beta(1)-subunits as a molecular mechanism of idiopathic ventricular fibrillation. J Mol Cell Cardiol 2000;32:1873-84.

29 Wan X, Chen S, Sadeghpour A, Wang Q, Kirsch GE. Accelerated inactivation in a mutant $\mathrm{Na}(+)$ channel associated with idiopathic ventricular fibrillation. Am J Physiol Heart Circ Physiol 2001 ;280:H354-60.

30 Dumaine R, Wang Q, Keating MT, Hartmann HA, Schwartz PJ, Brown AM, Kirsch GE. Multiple mechanisms of $\mathrm{Na}+$ channel-linked long-QT syndrome. Circ Res 1996;78:916-24.

31 Bennett PB, Yazawa K, Makita N, George AL Jr. Molecular mechanism for an inherited cardiac arrhythmia. Nature 1995;376:683-5.

32 Kirsch GE, Brown AM. Kinetic properties of single sodium channels in rat heart and rat brain. J Gen Physiol 1989;93:85-99.

33 Gintant GA, Datyner NB, Cohen IS. Slow inactivation of a tetrodotoxinsensitive current in canine cardiac Purkinje fibers. Biophys J 1984:45:509-12.

34 Snyders DJ, Hondeghem LM. Effects of quinidine on the sodium current of guinea pig ventricular myocytes. Evidence for a drug-associated rested state with altered kinetics. Circ Res 1990;66:565-79.

35 Tian X, Yong S, Wan X, Wu L, Chung MK, Tchou PJ, Rosenbaum DS, van Wagoner DR, Kirsch GE, Wang Q. Mechanisms by which SCN5A mutation N1325S causes cardiac arrythmias and sudden death in vivo. Cardiovasc Res 2004;61:256-7.

36 Makita N, Horie M, Nakamura T, Ai T, Sasaki K, Yokoi H, Sakurai M, Sakuma I, Otani H, Sawa H, Kitabatake A. Drug-induced long-QT syndrome associated with a subclinical SCN5A mutation. Circulation 2002;106:1269-74.
37 Makielski JC, Ye B, Valdivia CR, Pagel MD, Pu J, Tester DJ, Ackerman MJ. A ubiquitous splice variant and a common polymorphism affect heterologous expression of recombinant human SCN5A heart sodium channels. Circ Res 2003;93:821-8

38 Viswanathan PC, Benson DW, Balser JR. A common SCN5A polymorphism modulates the biophysical effects of an SCN5A mutation. J Clin Invest 2003;111:341-6.

39 Ye B, Valdivia CR, Ackerman MJ, Makielski JC. A common human SCN5A polymorphism modifies expression of an arrhythmia causing mutation. Physiol Genomics 2003:12:187-93.

40 Takahata T, Yasui-Furukori N, Sasaki S, Igarashi T, Okumura K, Munakata A, Tateishi T. Nucleotide changes in the translated region of SCN5A from Japanese patients with Brugada syndrome and control subjects. Life Sci 2003:72:2391-9.

41 An RH, Wang XL, Kerem B, Benhorin J, Medina A, Goldmit M, Kass RS. Novel LQT-3 mutation affects $\mathrm{Na}+$ channel activity through interactions between alpha- and beta-1 subunits. Circ Res 1998;83:141-6.

42 Veldkamp MW, Viswanathan PC, Bezzina C, Baartscheer A, Wilde AA Balser JR. Two distinct congenital arrhythmias evoked by a multidysfunctional $\mathrm{Na}(+)$ channel. Circ Res 2000;86:E91-7.

43 Yamagishi H, Furutani M, Kamisago M, Morikawa Y, Kojima Y, Hino Y, Furutani Y, Kimura M, Imamura S, Takao A, Momma K, Matsuoka R. A de novo missense mutation (R1623Q) of the SCN5A gene in a Japanese girl with sporadic long QT sydrome. Mutations in brief no. 140. Online. Hum Mutat 1998;11:481.

44 Ptacek L, George AL Jr, Barchi RL, Griggs RC, Riggs JE, Robertson M, Leppert M. Mutations in an S4 segment of the adult skeletal muscle sodium channel cause paramyotonia congenita Neuron 1992:8:891-87.

45 Makita N, Shirai N, Nagashima M, Matsuoka R, Yamada Y, Tohse N, Kitabatake A. A de novo missense mutation of human cardiac $\mathrm{Na}+$ channel exhibiting novel molecular mechanisms of long QT syndrome. FEBS Lett 1998:423:5-9.

46 Kambouris NG, Nuss HB, Johns DC, Tomaselli GF, Marban E, Balser JR Phenotypic characterization of a novel long-QT syndrome mutation (R1623Q) in the cardiac sodium channel. Circulation 1998;97:640-4.

47 Chahine M, George AL Jr, Zhou M, Ji S, Sun W, Barchi RL, Horn R. Sodium channel mutations in paramyotonia congenita uncouple inactivation from activation. Neuron 1994; 12:281-94.

48 Stuhmer W, Conti F, Suzuki H, Wang XD, Noda M, Yahagi N, Kubo H Numa S. Structural parts involved in activation and inactivation of the sodium channel. Nature 1989:339:597-603.

49 Cannon SC, Strittmatter SM. Functional expression of sodium channel mutations identified in families with periodic paralysis. Neuron 1993;10:317-26.

50 Mitrovic N, George AL Jr, Heine R, Wagner S, Pika U, Hartlaub U, Zhou M, Lerche $\mathrm{H}$, Fahlke $\mathrm{C}$, Lehmann-Horn $\mathrm{F}$. K(+)-aggravated myotonia: destabilization of the inactivated state of the human muscle $\mathrm{Na}+$ channel by the V1589M mutation. J Physiol 1994;478(Pt 3):395-402.

51 Bean BP, Cohen CJ, Tsien RW. Lidocaine block of cardiac sodium channels. J Gen Physiol 1983:81:613-42.

52 Dumaine R, Kirsch GE. Mechanism of lidocaine block of late current in long Q-T mutant Na+ channels. Am J Physiol 1998;274:H477-87. 